\title{
SÍNDROME DE PARSONAGE-TURNER: RELATO DE CASO EM PACIENTE HIV SOROPOSITIVO
}

\section{PARSONAGE-TURNER SYNDROME: CASE REPORT OF A HIV SEROPOSITIVE PATIENT}

Saulo Gomes de Oliveira', Eduardo Hosken Pombo ${ }^{2}$, Priscila Rossi de Batista ${ }^{3}$, Igor Machado Cardoso4, Rodrigo Rezende ${ }^{5}$

\section{RESUMO}

A síndrome de Parsonage-Turner é uma doença rara que acomete a musculatura da cintura escapular levando à hipotrofia muscular e grande déficit motor. A etiologia é indeterminada; acredita-se que existam fatores infecciosos e autoimunes envolvidos. $\mathrm{O}$ diagnóstico é de exceção, e os principais diagnósticos diferenciais são hérnias discais cervicais, lesões do manguito rotador e doenças reumáticas. Na investigação diagnóstica realizamos exames laboratoriais, radiografias e ressonância magnética dos ombros e da coluna cervical com destaque para a eletroneuromiografia auxiliando no diagnóstico definitivo. Por se tratar de uma doença raramente associada à soropositividade do vírus HIV e pela importância do diagnóstico precoce para o melhor tratamento destes pacientes é que relatamos este caso.

Descritores - Neurite do plexo braquial; HIV; Humanos

\section{ABSTRACT}

The Parsonage-Turner Syndrome is a rare disease that affects the muscles of the scapular girdle, leading to muscular atrophy and a large motor deficit. The etiology is unknown, but it is believed that infectious and autoimmune factors are involved. The diagnosis is made by exclusion, and the main differential diagnoses are cervical disc hernias, rotator cuff injuries and rheumatic diseases. During diagnostic research, we conducted laboratory tests, radiographs and MRI of the shoulder and cervical spine, with particular reference to electroneuromyography to help generate a definitive diagnosis. This case report is presented because it shows a disease that is rarely associated with HIV seropositivity and the importance of early diagnosis for better treatment of these patients.

Keywords - Brachial plexus neuritis; HIV; Humans

\section{INTRODUÇÃO}

A neuralgia amiotrófica da cintura escapular, também chamada de síndrome de Parsonage-Turner ou neurite braquial, foi inicialmente descrita por Dreschefeld em 1887, que relatou uma forma rara de atrofia muscular em duas irmãs. Diversos autores descreveram essa doença nos anos subsequentes, porém foram Parsonage e Turner, em 1948, que detalharam os aspectos clínicos da doença em uma coorte com 136 pacientes $^{(1-3)}$.

A incidência dessa síndrome é de dois a três indivíduos por 100.000 habitantes e ocorre principalmente entre a terceira e sétima décadas de vida. O sexo masculino é o mais acometido, variando de 2:1 a 11,5:1 em relação às mulheres $^{(3)}$. A etiologia ainda é desconhecida, porém acredita-se que existam fatores infecciosos e autoimunes envolvidos, pois $25 \%$ a $55 \%$ dos pacientes que manifestam a síndrome apresentam antecedentes de infecção e 15\% antecedentes recentes de imunização ${ }^{(3)}$. Dentre os agentes infecciosos existem relatos secundários a Parvovírus B19, vírus Epstein-Barr, Herpes vírus, Citomegalovírus e $\mathrm{HIV}^{(4)}$. Este relato de caso descreve um paciente com síndrome de Parsonage-Turner no estágio de soroconversão do vírus HIV, que é uma doença extremamente rara, com apenas cinco casos descritos na literatura mundial.

1 - Médico Residente (R3) de Ortopedia e Traumatologia, Vila Velha Hospital e Santa Casa de Vitória, ES.

2 - Ortopedista especialista em Cirurgia do Ombro e Cotovelo, Vila Velha Hospital, ES.

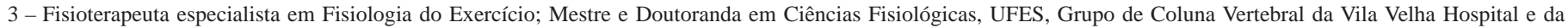
Santa Casa de Misericórdia de Vitória, ES.

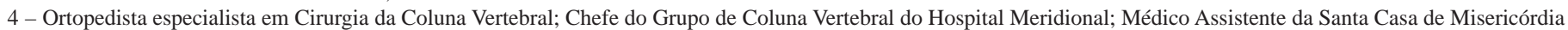
de Vitória e da Vila Velha Hospital, ES.

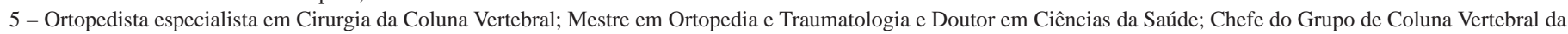
Vila Velha Hospital e da Santa Casa de Misericórdia de Vitória, ES. 


\section{RELATO DE CASO}

Paciente, sexo masculino, negro, porteiro, procedente de Vila Velha/ES, foi admitido no Serviço de Ortopedia e Traumatologia com queixa de dor na região cervical posterior, de forte intensidade, do tipo queimação, de início há 15 dias, com irradiação para membros superiores, associada à parestesia e grande limitação funcional dos ombros, principalmente rotação externa. Não foram observadas alterações dignas de nota na investigação de diversos órgãos e aparelhos e nos antecedentes pessoais. Apresentava antecedente de internação hospitalar havia uma semana, em que permaneceu por cinco dias para analgesia e investigação diagnóstica.

Ao exame físico observou-se hipotrofia da musculatura da cintura escapular, mais à esquerda, arco de movimento do ombro direito: $110^{\circ}, 0^{\circ}$ e $20^{\circ}$ e ombro esquerdo: $10^{\circ}, 10^{\circ}$ e $40^{\circ}$ para elevação, rotação externa e interna, respectivamente (Figuras 1, 2 e 3), parestesia em dermátomo correspondente a C5 e C6 e força muscular grau 2 nos movimentos do ombro direito e grau 3 no ombro esquerdo. Reflexos tendinosos bicipital, estiloideo e tricipital normais. Teste de Adson normal, Lermith negativo, Hoffman negativo, Neer negativo e Jobe negativo.

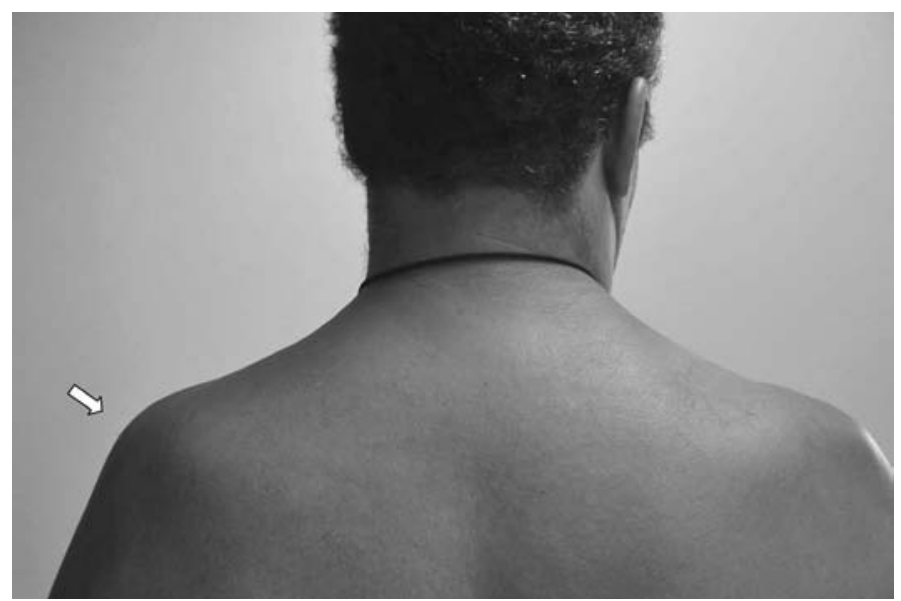

Figura 1 - Hipotrofia da musculatura da cintura escapular

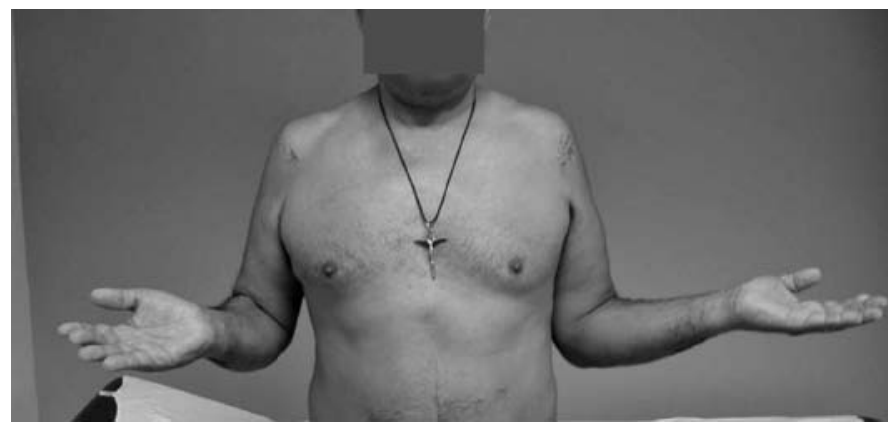

Figura 2 - Limitação da rotação externa bilateral

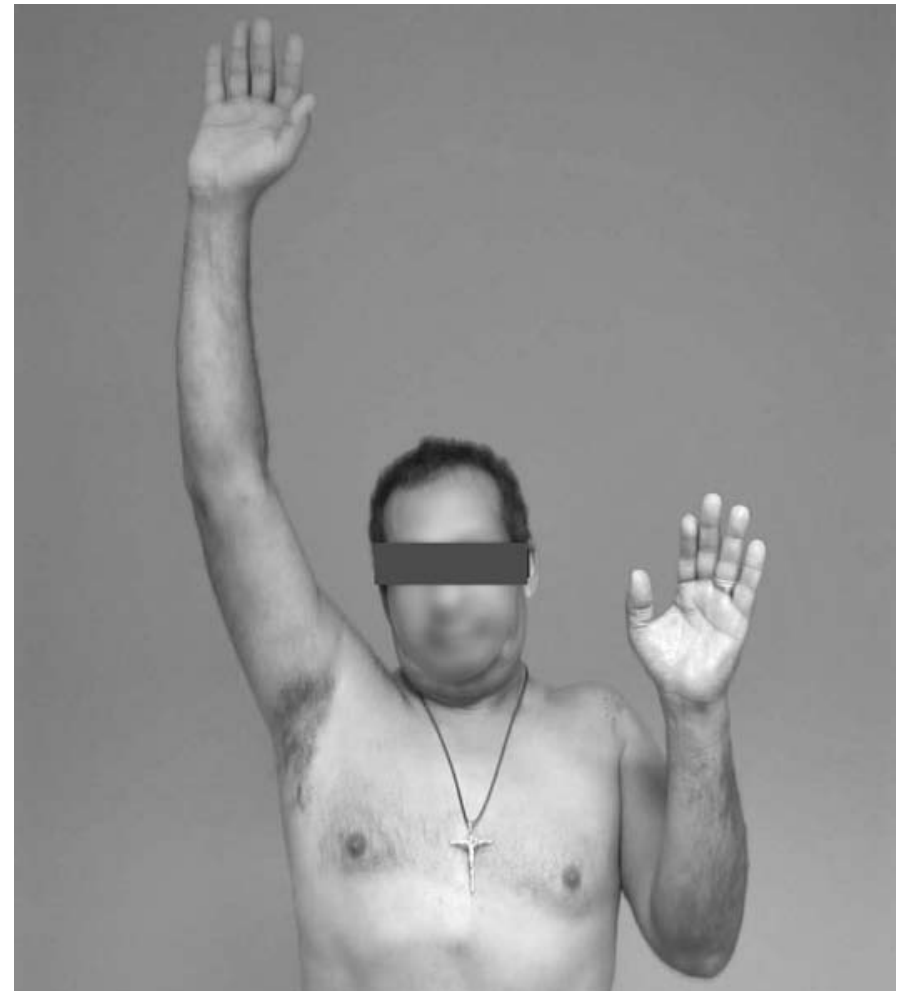

Figura 3 - Limitação da elevação do ombro esquerdo

Dentre os exames complementares realizados durante a investigação diagnóstica observou-se radiografias dos ombros e coluna cervical sem alterações, ressonância magnética (RM) da coluna cervical com presença de discopatia C2-C3 e C3-C4 sem compressão foraminal, RM do plexo braquial evidenciando presença de edema e infiltrado ao nível de plexo braquial e eletroneuromiografia (ENMG) demonstrando multineuropatia proximal braquial bilateral aguda sugestiva de neuralgia amiotrófica bilateral (Figuras 4 e 5).
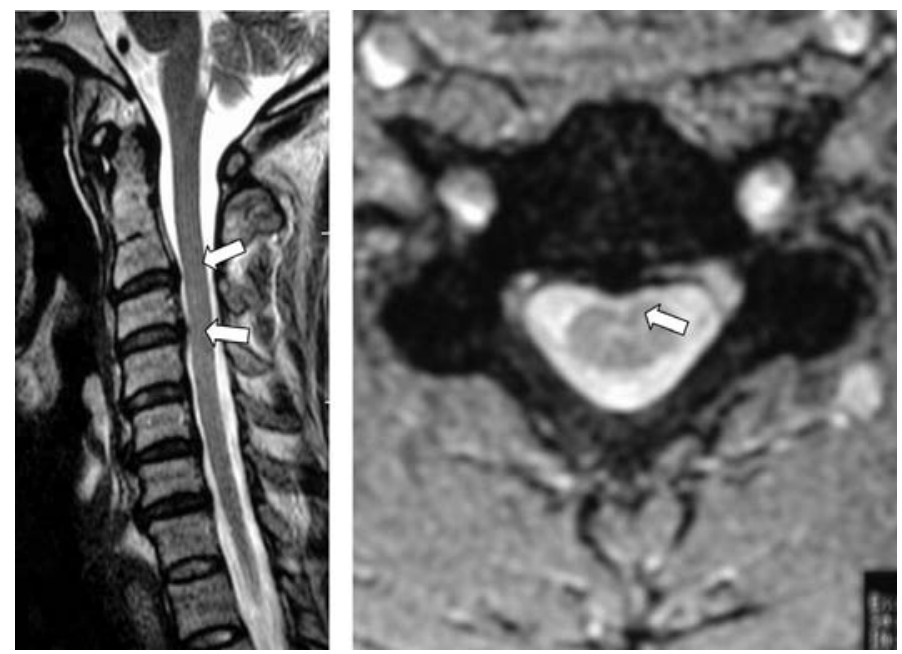

Figura 4 - RM de coluna cervical com presença de discopatia C2-C3, C3-C4 

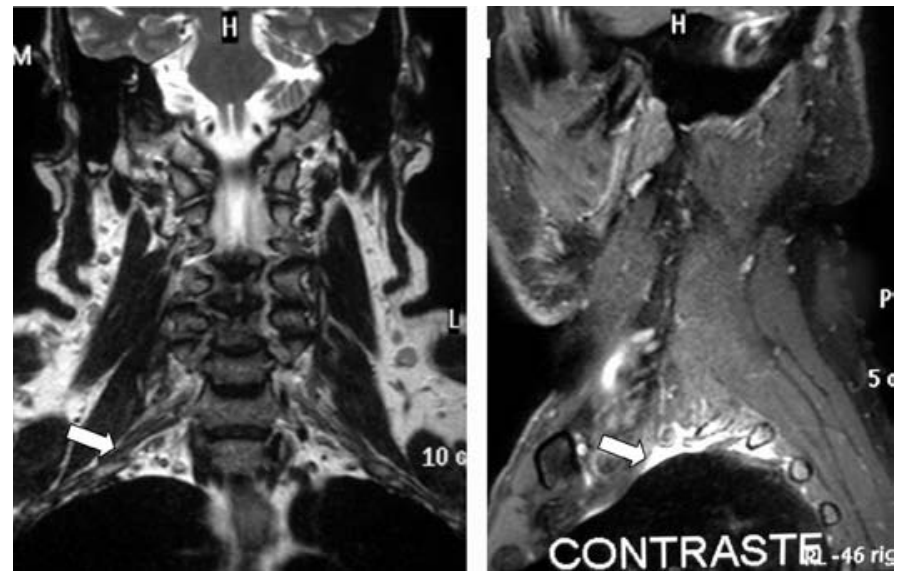

Figura 5 - RM de plexo braquial com presença de edema e infiltrado

Exames laboratoriais: hemograma com hemoglobina de 13,2g/dL, hematócrito 40,5\%, anisocitose $(+)$, leucócitos $3.000 / \mathrm{mm}^{3}$ (bastonetes 1\%, segmentados 60\%, linfócitos 30\%, eosinófilos 7\%, monócitos 2\%) e plaquetas $192.000 / \mathrm{mm}^{3}$, VHS 65mm, PCR inferior a $6,0 \mathrm{mg} / \mathrm{dL}, \mathrm{Na} 138 \mathrm{mEq} / \mathrm{L}, \mathrm{K} 4,5 \mathrm{mEq} / \mathrm{L}$, cálcio total 8,0mg/dL, AST 78,0 U/L (VR: 3 a 37U/L), ALT 44,0U/L (VR: 3 a 65U/L), albumina sérica 3,9g/dL (VR: 3,5 a 5,5g/dL). Parasitológico de fezes: Endolimax nana $(++)$ e anti-HIV reativo com segunda amostra posterior reativa. Os exames FAN, fator reumatoide, anti-HBc, anti-HCV e VDRL foram não reativos.

Sendo diagnosticada síndrome de Parsonage-Turner secundária a processo viral agudo pelo HIV, iniciou-se tratamento medicamentoso com infectologista e tratamento analgésico e reabilitação intensiva dos membros superiores. Após um ano houve melhora progressiva dos sintomas com retorno da força motora completa e do arco de movimento da cintura escapular. Foi solicitada nova eletroneuromiografia de membros superiores após um ano sendo observada sequela de multineuropatia axonal proximal bilateral com ausência de sinais de desnervação ativa (Figuras 6 e 7).

\section{DISCUSSÃO}

A síndrome de Parsonage-Turner é um processo patológico raro e acomete principalmente a cintura escapular. A evolução do quadro ocorre em dois períodos distintos, iniciando com dores intensas no ombro, geralmente o direito ( $20 \%$ bilateralmente), estendendo-se para o membro superior; alguns dias ou semanas depois as dores atenuam e surge paralisia flácida. A apresentação clínica e a perda da sensação dependem do nervo acometido; nervo frênico pode estar acometido em 5\%

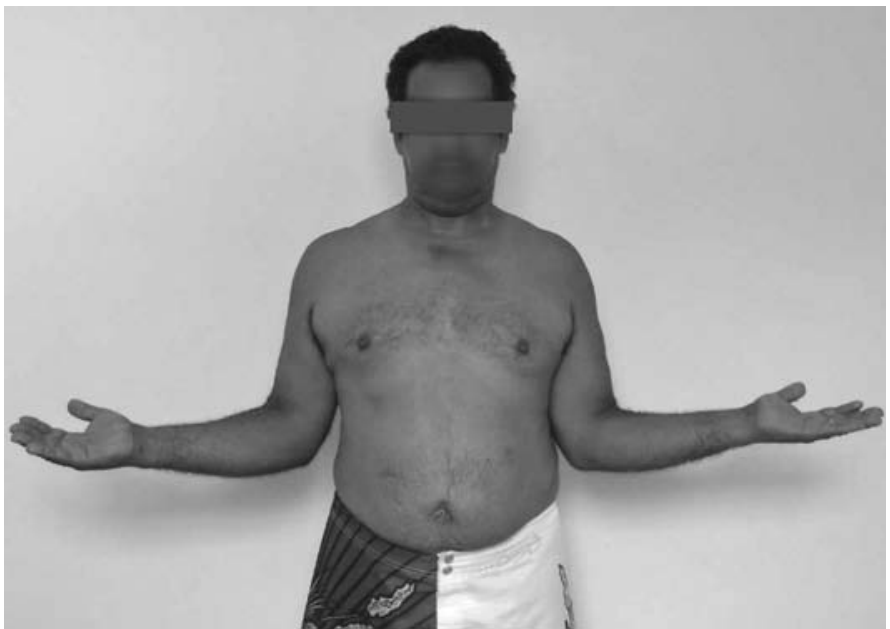

Figura 6 - Rotação externa de $45^{\circ}$ bilateral após um ano de acompanhamento

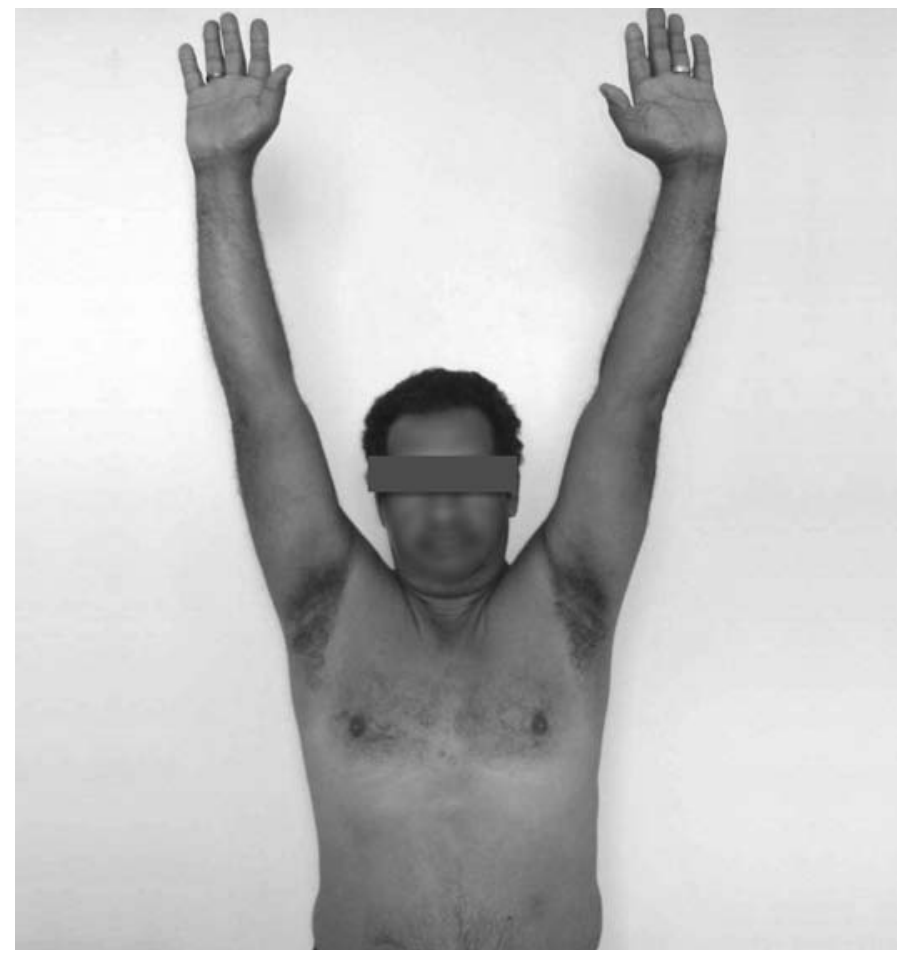

Figura 7 - Elevação de $130^{\circ}$ após um ano de acompanhamento

dos casos, acarretando evolução desfavorável. A evolução das alterações motoras é parcialmente regressiva e, em um ano, há recuperação parcial a total de aproximadamente $1 / 3$ dos pacientes, e $90 \%$ dos pacientes recuperam-se dentro de três anos. Em dois anos, o risco de incapacidade residual significante é de aproximadamente $20 \%$ e a recorrência é de $5 \%{ }^{(5-7)}$.

Durante a primeira avaliação deste paciente observamos que, além da dor de forte intensidade na região cervical e nos ombros, que levou o paciente a internação hospitalar prévia em outro serviço para analgesia, o paciente apresentava hipotrofia e paralisia flácida da 
musculatura da cintura escapular, dados que nos levaram a pensar inicialmente em hanseníase, miopatia inflamatória ou infecção aguda viral. Inicialmente descartamos hanseníase e miopatia inflamatória devido à pesquisa de BAAR negativa e dosagem de enzimas musculares normais. Descartamos a hipótese de radiculopatia secundária à compressão cervical pela ausência de intensificação da dor com a mobilidade cervical, presença de reflexos normais (com testes de Brudizinski e Lermith negativos) e investigação complementar com radiografias e ressonância magnética da coluna cervical sem alterações. Descartamos também lesões do manguito rotador, pois o paciente não apresentava alterações nos testes especiais de Neer e Jobe, além de exames de imagem dos ombros sem alterações.

Passamos, então, a ter como principal hipótese diagnóstica a síndrome de Parsonage-Turner sendo solicitados exames laboratoriais de rotina, sorologias para detecção de doenças virais e ENMG dos membros superiores. Nos exames sanguíneos foram observados anti-HIV reativo e ENMG evidenciando neuralgia amiotrófica. Foram descartados ainda compressões extrínsecas no plexo braquial e sinais inflamatórios nas suas raízes com RM.
Iniciamos o tratamento com forte esquema analgésico por 20 dias, com melhora progressiva e fisioterapia intensiva para ganho de movimento e fortalecimento muscular da cintura escapular, além de acompanhamento com infectologista.

Após um ano de seguimento não tivemos recorrência de crises álgicas; houve importante melhora na força muscular e do arco de movimento, estando atualmente em 120, 90 e 40 graus de elevação, rotação externa e rotação interna, respectivamente, em ambos os ombros, e a ENMG identificou melhora da resposta eletroneuromiográfica sem sinais de desnervação aguda.

Em conclusão, a síndrome de Parsonage-Turner é uma doença rara que normalmente é avaliada pelo ortopedista socorrista e tem diagnóstico erroneamente feito de hérnia cervical ou lesão do manguito rotador. Estes pacientes, muitas vezes sem diagnóstico, evoluem com grande hipotrofia da musculatura da cintura escapular, sendo irreversível o retorno à função normal do ombro devido à ausência de reabilitação adequada precoce. $\mathrm{O}$ diagnóstico de síndrome de Parsonage-Turner deve ser lembrado nos casos de dor súbita de forte intensidade na região cervical e nos ombros com presença de paralisia flácida.

\section{REFERÊNCIAS}

1. Parsonage MJ, Turner JW. Neuralgic amyotrophy; the shoulder-girdle syndrome. Lancet. 1948;1(6513):973-8.

2. Turner JWA, Parsonage MJ. Neuralgic amyotrophy (Paralytic Brachial Neuritis) with special reference to prognosis. Lancet. 1957;273(6988):209-12.

3. Sathasivam S, Lecky B, Manohar R, Selvan A. Neuralgic amyotrophy. J Bone Joint Surg Br. 2008;90(5):550-3.

4. Rachid A, Bem RS, Lacerda D, Seitenfus JL. Síndrome de Parsonage-Turner em paciente HIV positivo. Rev Bras Reumatol. 2005;45(1):39-42.

5. McCarty EC, Tsairis P, Warren RF. Brachial neuritis. Clin Orthop Relat Res. 1999;(368):37-43.

6. Ashworth NL. Brachial Neuritis. eMedicine. Disponível em: http://www.emedicine. com/pmr/topic58.htm

7. Cambier J, Masson M, Dehen H. Manual de neurologia. 2a ed. São Paulo: Atheneu; 1998. 